\title{
Cales noacki Howard, 1907 (Hymenoptera: Aphelinidae) ile Aleurothrixus floccosus Maskell, 1896 (Homoptera: Aleyrodidae) arasindaki ilişkilerin belirlenmesi
}

\author{
Gonca (VATANSEVER) SAKİN ${ }^{1, *}$, Mehmet Rifat ULUSOY ${ }^{2}$ \\ ${ }^{1}$ Balıkesir Üniversitesi, Edremit Meslek Yüksek Okulu, 10300 Edremit-Balıkesir, Türkiye \\ ${ }^{2}$ Çukurova Üniversitesi, Ziraat Fakültesi, Bitki Koruma Bölümü, O1330 Balcalı-Adana, Türkiye \\ Geliş Tarihi (Recived Date): 31.10 .2018 \\ Kabul Tarihi (Accepted Date): 26.01.2019
}

\section{Özet}

Turunçgil pamuklu beyazsineği, Aleurothrixus floccosus Maskell, 1896 (Homoptera: Aleyrodidae) ve parazitoiti, Cales noacki Howard, 1907 (Hymenoptera: Aphelinidae)'nin laboratuvar koşullarında konukçu-parazitoit ilişkileri incelenmiştir. C. noacki'ye A. floccosus'un tüm ergin öncesi dönemleri ayr ayr verildiğinde; parazitoitin beyazsineğin tüm larva dönemlerini parazitlediği, ancak en fazla 2. larva dönemini (\%29.8), daha sonra da 3. larva dönemini (\%21.8) parazitlediği belirlenmiştir. A. floccosus'un ergin öncesi dönemlerinin tümü bir arada verildiğinde ise C. noacki yine en fazla beyazsineğin 2. larva dönemini (\%27.6) daha sonra 3. larva dönemini (\%17.4) tercih etmiştir. Parazitoitin ergin dişileri yaşamlart süresince ortalama $37.6 \pm 1.17$ adet yumurta birakmışlardır. C. noacki'ye 5, 10, 25, 50, 100 ve 150 adet beyazsineğin 2. larva dönemi verildiğinde; parazitoit en fazla 50 birey (\%78.4) ve altındaki sayılarda beyazsineği parazitlediği belirlenmiştir. C. noacki’nin, farklı A. flocosus yoğunluklarında Holling'in II. Tipte işlevsel tepki ĕgrisi oluşturduğu ve $R^{2}$ de ğerinin oldukça yüksek (0.967) olduğu tespit edilmiştir.

Anahtar Kelimeler: Cales noacki, Aleurothrixus floccosus, yaşam süresi, işlevsel tepki.

\footnotetext{
* Gonca SAKİN, goncav@balikesir.edu.tr, https://orcid.org/0000-0003-1046-2455

Mehmet Rifat ULUSOY, mrulusoy@cu.edu.tr, https://orcid.org/0000-0001-6610-1398
} 


\title{
Determination of relationships between Cales noacki, 1907 \\ (Hymenoptera: Aphelinidae) with Aleurothrixus floccosus \\ Maskell, 1896 (Homoptera: Aleyrodidae)
}

\begin{abstract}
Host-parasitoid relationship between citrus wooly whitefly, Aleurothrixus floccosus Maskell, 1896 (Homoptera: Aleyrodidae) and parasitoid, Cales noacki Howard, 1907 (Hymenoptera: Aphelinidae) was investigated in laboratory conditions. When all the immature stages of A. floccosus were given separately, it was observed that $C$. noacki could parasitized all the stages. However, the rate of the parasitization was the highest in the second larval stage (29.8\%) and then in the third larval stage (21.8\%). Also when all immature stages of A. floccosus were given together, $C$. noacki preferred the second larval stage (27.6\%) and then the third larval stage (17.4\%). The parasitoid females laid an average of $37.6 \pm 1.17$ eggs during their lifetime. C. noacki parasitized up to 50 individuals $(78,4 \%)$ or below of whiteflies when the parasitoid was given with the number of 5, 10, 25, 50, 100 or 150 larvae of whiteflies in the second larval stage. It was defined that the parasitoid showed Holling's type II functional response in different quantities of $A$. flocosus and the $R^{2}$ value was to be quite high (0.967).
\end{abstract}

Keywords: Cales noacki, Aleurothrixus floccosus, lifetime, functional response.

\section{Giriş}

Turunçgil pamuklu beyazsineği, Aleurothrixus floccosus Maskell (Homoptera: Aleyrodidae)'nin spesifik parazitoiti olan Cales noacki Howard (Hymenoptera: Aphelinidae), Güney Amerika'dan Avrupa'ya kadar yayılmış [1,2] ve ilk kez 1966 yılında Fransa' da görülmüştür [3]. Türkiye'de ise 1994 yılında A. floccosus ile birlikte Hatay (Harbiye) (Doğu Akdeniz Bölgesi)'de tespit edilmiştir [4].

C. noacki'nin, A. floccosus ile mücadelede kimyasal ilaçlardan çok daha fazla etkili olduğu ve konukçusunu rahatlıkla baskı altına alabildiği bildirilmiştir [5-9]. Bundan dolayı C. noacki'nin, zararlının biyolojik mücadelesinde en etkili doğal düşmanı olduğu ve bir çok ülkede beyazsineğin mücadelesinde başarılı bir şekilde kullanıldığı bilinmektedir [10-14].

A. floccosus 'un en etkili doğal düşmanı olan C. noacki 'nin zararlıyı kolaylıkla baskı altına alabilmesi ve Türkiye'de var olması ülkemiz turunçgil üretimi için ümitvar bir durumdur $[4,15]$. Özellikle $C$. noacki'nin doğadaki etkinliğinin belirlenebilmesine temel oluşturması amacıyla, bu çalışmada A. floccosus ve parazitoit arasındaki ilişkiler laboratuvar koşullarında çalışılmıştır.

\section{Deneysel çalışmalar}

\subsection{Cales noacki ile Aleurothrixus floccosus üretim çalsşmaları}

C. noacki üretiminde konukçu bitki olarak turunç (Citrus aurantium L.) fidanları kullanılmıştır. Bu fidanlar üzerinde öncelikli olarak beyazsinek üretim odasında $A$. floccocus üretimi, bir diğer iklim odasında ise C. noacki üretimi yapılmıştır. Bu amaçla 
üzerinde $A$. floccosus'un farklı dönemlerinin bulunduğu yeterli sayıda turunç fidanı $C$. noacki üretim odasına yerleştirilmiştir. Üretimlerin devamlılığını sağlamak amacıyla her ay düzenli olarak turunç ekim ve dikimi yapılmış olup, gerek duyuldukça beyazsinek üretimine yeni turunç fidanları, parazitoit odasına ise üzerinde bol miktarda beyazsinek bulunan fidanlar yerleştirilmiştir.

A. floccosus ve $C$. noacki üretimleri, $26 \pm 1{ }^{0} \mathrm{C}$ sicaklık ile $\% 70 \pm 5$ orantılı neme ayarlı ve 16:8 saat aydınlatmalı iklim odalarında yürütülmüştür.

\subsection{Aleurothrixus floccosus'u parazitlemede Cales noacki'nin tercih ettiği dönemlerin saptanması}

C. noacki'nin yumurta birakmak için tercih ettiği konukçu dönemini belirlemek amacıyla iki farklı deneme kurulmuştur. Birinci denemede A. floccosus'un herbir dönemini (1., 2. ve 3. evre larvalar ile pupa evresi) ayrı ayrı ve eşit sayıda üzerinde bulunduran üçer adet fidan hazırlanmıştır. Daha sonra bu fidanlar iklim dolabına yerleştirilerek üzerlerine, tabanına tül geçirilen pet kavanozlar geçirilmiş, herbirinin içerisinde ayrı ayrı onar adet $(5 q$ ve 5 §̂) pupadan yeni çıkmış $C$. noacki ergini salınmıştır. İkinci denemede ise A. floccosus'un herbir dönemini ayrı ayrı ve eşit sayıda üzerinde bulunduran üçer adet fidan birarada tutulmuş ve üzerlerine toplam 10 adet (5 $q$ ve 5 ふ) $C$. noacki ergini salınmıştır.

Parazitoit erginlerinin beslenmeleri için kavanozların içerisine şekerli su (\%10'luk) emdirilmiş küçük sünger parçacığı konulmuş erginler 24 saat süreyle A. floccosus larvaları ile birarada tutulduktan sonra ortamdan uzaklaştırılmışlardır. Daha sonra günlük kontrollerle, parazitlenen A. floccosus'un ergin öncesi dönemleri tespit edilerek sayımları yapılmış ve bu şekilde parazitoitin beyazsineğin hangi dönemlerini tercih ettiği ortaya çıkarılmıştır.

Denemeler $26 \pm 1{ }^{0} \mathrm{C}$ sıcaklık, \%70 \pm 10 orantılı nem ve 16 saat aydınlatmalı koşullara sahip iklim dolaplarında yürütülmüş ve her iki deneme de beşer kez tekrarlanmıștır.

\subsection{Cales noacki'nin Aleurothrixus floccosus'u parazitlemede tercih ettiği döneme biraktı̆̆ yumurta sayısının saptanmast}

C. noacki'nin $A$. floccosus'un ergin öncesi dönemlerinden hangisini tercih ettiği belirlendikten sonra, bu döneme bıraktığı yumurta sayısını saptamak amacıyla, 50 adet turunç fidanı üzerine 24 saat süreyle çok sayıda A. floccosus ergini salınmış ve erginlerin yumurta bırakmaları sağlanmıştır. Bu fidanlar daha sonra iklim dolabına alınarak A. floccosus bireyleri $C$. noacki'nin tercih ettiği döneme gelinceye kadar bekletilmiştir. Sonra herbir fidan üzerinde en az 100 adet aynı dönem larva bırakılmış ve bunlar üzerine pupadan yeni çıkmış döllenmiş ancak daha önce yumurta bırakmamış birer adet $C$. noacki ergin dişisi salınmıştır. Parazitoit erginleri ölünceye kadar bu fidanlar üzerinde bekletilmiş ve daha sonra fidanlar üzerindeki beyaz sinek larva ve pupaları kontrol edilerek parazitlenenler sayılmıştır.

\subsection{Cales noacki'nin Aleurothrixus floccosus yoğunluğuna bağlı olarak parazitleme gücünün saptanmast}

Turunç fidanlarının üzerine çok sayıda A. floccosus erginleri salınarak yumurta bırakmaları sağlanmıștır. Bu fidanlar C. noacki'nin A. floccosus'u parazitlediği döneme kadar bekletilmiş ve fidanlar iklim dolabına alınarak herbir A. floccosus yoğunluğu üzerine $(5,10,25,50,100,150$ A. floccosus bireyi (adet/yaprak)) ayrı ayrı olmak üzere 
pupadan yeni çıkmış birer adet ergin dişi parazitoit salınmıştır. Salımdan 24 saat sonra parazitoit erginleri ortamdan uzaklaştırılmıştır.

A. floccosus pupaları üzerinde parazitli bireyler ortaya çıktığında sayımları yapılmış ve C. noacki'nin A. floccosus yoğunluğuna bağlı olarak parazitleme gücü tespit edilmiştir. Denemeler 10 tekrarlı olarak yürütülmüştür. $C$. noacki ve A. floccosus arasındaki ilişkilerin saptanması $26 \pm 1{ }^{0} \mathrm{C}$ sıcaklık, $\% 70 \pm 10$ orantılı nem ve 16 saat aydınlatmalı koşullara sahip iklim dolaplarında yürütülmüştür.

Çalışmalardan elde edilen sonuçların analizleri, SPSS 10.0 paket programında hesaplanmış ve ortalamalar varyans analizine (ANOVA) tabi tutulmuştur [16, 17]. Ortalamalar arasında farkın olup olmadığının anlaşılması için de ortalamalar Duncan'ın çoklu karşılaştırma testi ile değerlendirilmiştir.

C. noacki'nin işlevsel tepkisi, doğada böcek predatör ve parazitoitleri arasında en yaygın şekilde görülen Holling'in II. tip işlevsel tepki olduğu varsayılarak, bunu tanımlayan [18] disk denkliği denklemi;

$N_{a}=\frac{a \cdot N \cdot T}{1+a \cdot N \cdot T_{h}}$

ile hesaplanmıştır.

$N=$ verilen konukçu sayısı

$N_{a}=$ parazitlenen konukçu sayısı

$T=$ deneme süresi

$a=$ parazitoitin konukçusunu arama bulma oranı

$T_{h}=$ parazitoitin konukçusunu arama ve beslenmesi için geçen süre.

İşlevsel tepki ve buna bağlı parametreler, SYSTAT 10.2 paket programı kullanılarak hesaplanmıştır.

\section{Sonuçlar ve tartışma}

\subsection{Aleurothrixus floccosus'u parazitlemede Cales noacki'nin tercih ettiği dönemler}

Tablo 1.'de görülebileceği gibi $C$. noacki'ye A. floccosus'un tüm dönemleri ayrı ayrı verildiğinde, parazitoit beyazsineğin tüm ergin öncesi dönemlerini parazitlemiştir. Ancak, dönemler içerisinde en fazla ikinci larva dönemini \%29.8 oranında parazitlerken, daha sonra sırasıyla üçüncü larva dönemini $\% 21.8$, birinci larva dönemini $\% 11.6$ ve pupa dönemini $\% 7.0$ oranında oranında parazitlediği tespit edilmiştir. $\mathrm{Bu}$ sonuçlara göre, parazitoit dişilerinin yumurta bırakmak için en fazla A. floccosus'un ikinci ve üçüncü larva dönemlerini tercih ettiği anlaşılmaktadır. Parazitoit çok az da olsa birinci larva ve pupa dönemine de yumurta bırakmıştır.

C. noacki'ye A. floccosus'un ergin öncesi dönemlerinin tümü birarada verildiğinde, yani parazitoitin beyazsineğin hangi dönemlerini daha çok parazitlediğini belirlemek için yapılan denemede elde edilen sonuçlar Tablo 2.'de verilmiştir. Bir önceki denemede görüldüğü gibi bu denemede de parazitoit yine en fazla \%27.6 oranında beyazsineğin ikinci larva dönemini daha sonra da \%17.4 oranında üçüncü larva dönemini 
parazitlemiştir (Tablo 2). C. noacki, A. floccosus'un birinci larva ve pupa dönemlerini de eşit oranda (\%4.4) parazitlemiştir. Bu sonuçlardan da anlaşılabileceği gibi, $C$. noacki'ye A. floccosus'un ergin öncesi larva dönemlerinin tümü bir arada verildiğinde parazitoitin en çok ikinci daha sonra da üçüncü larva dönemini tercih ettiği saptanmıştır.

Tablo 1. Cales noacki erginlerine Aleurothrixus floccosus ergin öncesi dönemleri ayrı ayrı verildiğinde parazitoitin parazitleme durumu (Adet \pm S.H.).

\begin{tabular}{ccccc}
\hline \hline $\begin{array}{c}\text { A. floccosus } \\
\text { Dönemleri }\end{array}$ & $\begin{array}{c}\text { C. noacki } \\
\text { (n) }\end{array}$ & $\begin{array}{c}\text { A.floccosus } \\
(\mathrm{n})\end{array}$ & $\begin{array}{c}\text { Parazitli } \\
\text { A. floccosus } \\
(\mathrm{n})\end{array}$ & $\begin{array}{c}\text { A. floccosus'un } \\
\text { parazitlenme } \\
\text { oran1 (\%) }\end{array}$ \\
\hline 1. Larva & 15 & 50 & $5.8 \pm 0.45 \mathrm{c}$ & 11.6 \\
2. Larva & 15 & 50 & $14.9 \pm 1.09 \mathrm{a}$ & 29.8 \\
3. Larva & 15 & 50 & $10.9 \pm 0.53 \mathrm{~b}$ & 21.8 \\
Pupa & 15 & 50 & $3.5 \pm 0.49 \mathrm{~d}$ & 7.0 \\
\hline
\end{tabular}

* n C. noacki ve A. floccosus sayısını belirtmektedir.

** Ortalamalar arasındaki fark yukarıdan aşağıya izlendiğinde aynı harfi içermiyorsa Duncan'ın çoklu karşılaştırma testine göre istatistiki olarak önemlidir $(\mathrm{P}=0.05)$.

Tablo 2. Cales noacki erginlerine Aleurothrixus floccosus ergin öncesi dönemlerinin tümü birarada verildiğinde parazitoitin parazitleme durumu (Adet \pm S.H.).

\begin{tabular}{|c|c|c|c|c|}
\hline $\begin{array}{l}\text { A. floccosus } \\
\text { Dönemleri }\end{array}$ & $\begin{array}{c}\text { C. noacki } \\
\mathrm{n}\end{array}$ & $\begin{array}{c}\text { A. floccosus } \\
\mathrm{n}\end{array}$ & $\begin{array}{c}\text { Parazitli } \\
\text { A. floccosus } \\
\mathrm{n}\end{array}$ & $\begin{array}{c}\text { A. floccosus'un } \\
\text { parazitlenme } \\
\text { oran1 }(\%)\end{array}$ \\
\hline 1. Larva & 15 & 50 & $2.2 \pm 0.43 \mathrm{c}$ & 4.4 \\
\hline 2. Larva & 15 & 50 & $13.8 \pm 0.93 a$ & 27.6 \\
\hline 3. Larva & 15 & 50 & $8.7 \pm 0.58 b$ & 17.4 \\
\hline Pupa & 15 & 50 & $2.2 \pm 0.38 c$ & 4.4 \\
\hline
\end{tabular}

* n C. noacki ve A. floccosus sayısını belirtmektedir.

** Ortalamalar arasındaki fark yukarıdan aşağıya izlendiğinde aynı harfi içermiyorsa Duncan'ın çoklu karşılaştırma testine göre istatistiki olarak önemlidir $(\mathrm{P}=0.05)$.

Yapılan iki farklı denemenin sonuçları birlikte değerlendirildiğinde; A. floccosus'un larva ve pupa dönemleri $C$. noacki'ye ayrı ayrı veya tümü birarada verildiğinde, parazitoit dişilerinin yumurta birakmak için en fazla ikinci larva, daha sonra da üçüncü larva dönemini tercih ettiği açıkça görülmektedir. Diğer taraftan A. floccosus'un birinci larva ve pupa dönemleri parazitoite ayrı ayrı ve hepsi bir arada verildiğindeki parazitlenme oranlarına birlikte baktığımızda ayrı ayrı verildiğinde daha fazla oranda parazitlenmişlerdir. Sonuçta, $C$. noacki' nin birinci larva veya pupa dönemini pek fazla tercih etmediği, ancak mecbur kaldığında bu dönemleri de parazitleyeceği kanısına varılmıştır (Tablo 1-2. ve Şekil 1). Benzer şekilde yapılan bir çalışmada C. noacki'nin, beyazsineğin öncelikle ikinci ve üçüncü larva dönemini tecih ettiğini, birinci larva dönemini ise hiç tercih etmediği bildirilmiştir [19]. Diğer bir çalışmada da, $C$. noacki'nin A. floccosus'un ikinci ve üçüncü larva dönemine yumurta bıraktığını bildirmişlerdir [20]. 


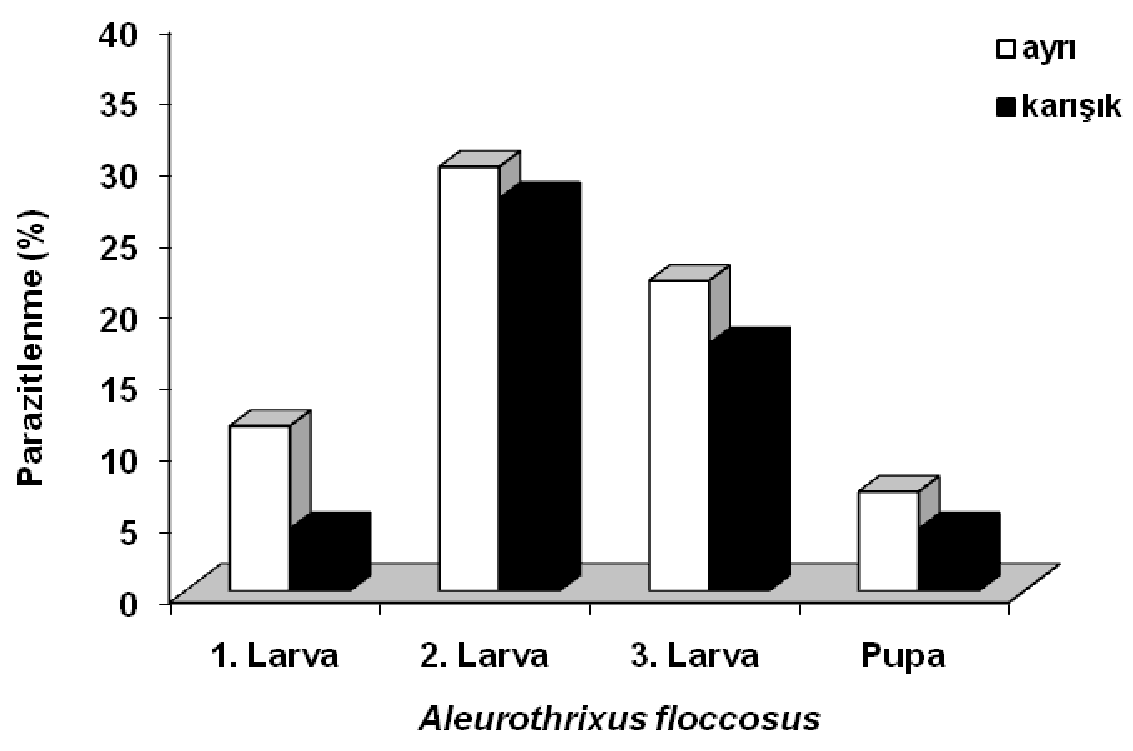

Şekil 1. Cales noacki erginlerine Aleurothrixus floccosus ergin öncesi dönemleri ayrı ayrı ve tümü bir arada verildiğinde, beyazsineğin parazitlenme durumu.

\subsection{Cales noacki'nin Aleurothrixus floccosus'u parazitlemede tercih ettiği döneme buraktı̆̆ yumurta sayısı}

Pupadan yeni çıkmıș herbir $C$. noacki erginine $A$. floccosus'un ikinci larva dönemleri verilmiş ve bu işlem $46 \mathrm{kez}$ tekrarlanmıştır. Deneme süresince \%10'luk şekerli su verilen $C$. noacki dişileri yaşamları süresince ortalama $37.6 \pm 1.17$ adet, en az beș en fazla da 48 adet yumurta bırakmıştır. C. noacki dişilerinin ömrü boyunca ortalama 41.5 adet $A$. floccosus'u parazitlediği ve parazitoitin en fazla yumurtayı yaşamının ikinci gününde bıraktığı bildirilmiştir [19]. Benzer şekilde ortalama 12.2 gün yaşayan $C$. noacki dişilerinin ortalama 47.4 adet yumurta bıraktıkları tespit edilmiştir [21]. Bu çalışmada $C$. noacki dişilerinin bıraktığı yumurta sayıları literatürde bildirilen sonuçlarla benzerlik göstermektedir.

\subsection{Cales noacki'nin Aleurothrixus floccosus yoğunluğuna bağlı olarak parazitleme güiü}

C. noacki, A. floccosus ile bir gün süreyle aynı ortamda bırakıldığında beyazsinek yoğunluğu arttıkça, parazitlediği birey sayısında belirgin bir artış olduğu ortaya çıkarılmıştır (Tablo 3). Parazitoite, 5 ve 10 adet $A$. floccosus larvası verildiğinde, parazitlenen birey sayıları arasında istatistiki olarak bir fark bulunmamıştır. Benzer şekilde $C$. noacki'ye $A$. floccosus'un 50, 100 ve 150 larva yoğunlukları verildiğinde her ne kadar istatistiki olarak fark ortaya çıkmışsa da, parazitlenen birey sayıları biribirlerine oldukça yakın bulunmuştur. En fazla parazitlenen birey sayısı, parazitoite 150 adet beyazsinek larvası verildiği zaman gerçekleşmiştir (Tablo 3). Parazitlenen birey sayısında 50 bireye kadar iki kat artış görülmüş olup, sonrasında artış devam etmiş, ancak artış çok düşük seviyelerde kalmıştır (Tablo 3). Bu düşük av yoğunluğunda parazitoitin neslini devam ettirebilmek için, az sayıdaki konukçuya az sayıda yumurtalarını bırakma eğiliminde olmasına bağlayabiliriz. Diğer taraftan $C$. noacki'nin parazitleme gücünün 100 adet A. floccosus yoğunluğu civarında olduğu, nitekim, 50, 100 ve 150 birey yoğunluğunda parazitoitin 50'nin altında bir parazitleme yaptığı da açıkça görülmektedir (Tablo. 3). Bu yoğunluktan sonra, belki de $A$. floccosus'un popülasyonunun artmasıyla beraber salgılanan balımsı maddenin de 
artması ve bundan dolayı parazitoitin konukçusunu aramada zorluk çekme ve daha fazla bireyi parazitleyememe gibi bir sorun yaşadığı kanısına da varılabilir. A. floccosus'un ikinci larva döneminde başlayan balımsı madde salgılaması, daha sonraki dönemlerinde yoğun şekilde devam etmekte ve son dönemlerine doğru yüksek popülasyonlarda pupadan çıkmaya çalışan beyazsinek ya da parazitoit erginlerinin ölümlerine dahi neden olduğu da gözlenmiştir.

Tablo 3. Cales noacki' nin farklı yoğunluklardaki Aleurothrixus floccosus popülasyonunu parazitleme gücü (Adet \pm S.H.).

\begin{tabular}{|c|c|c|c|}
\hline $\begin{array}{l}\text { A. floccosus } \\
\text { yoğunluğu } \\
(\mathrm{n})^{*}\end{array}$ & $\begin{array}{c}\text { C. noacki } \\
\mathrm{n}\end{array}$ & $\begin{array}{c}\text { Parazitli } \\
\text { A. floccosus sayıs } \\
\mathrm{n}\end{array}$ & $\begin{array}{c}\text { A. floccosus'un } \\
\text { parazitlenme oranı } \\
(\%)\end{array}$ \\
\hline 5 & 20 & $3.7 \pm 0.24 d$ & 74.0 \\
\hline 10 & 15 & $7.6 \pm 0.49 \mathrm{~d}$ & 76.0 \\
\hline 25 & 20 & $19.3 \pm 0.80 c$ & 77.2 \\
\hline 50 & 20 & $39.2 \pm 1.52 b$ & 78.4 \\
\hline 100 & 69 & $45.2 \pm 1.79 \mathrm{ab}$ & 45.2 \\
\hline 150 & 19 & $48.4 \pm 3.57 \mathrm{a}$ & 32.3 \\
\hline
\end{tabular}

A. floccosus'un parazitlenme oranına baktığımızda; 5 larva yoğunluğunda \%74 olan parazitlenme oranı, birey sayısı arttıkça hafifçe artmış ve 50 birey yoğunluğunda \%78.4'e kadar ulaşmıştır. Parazitoitin 100 adet beyazsinek yoğunluğunda ise parazitleme oranında belirgin bir düşüş görülmüş ve 150 bireyde bu oran \%32.3'e kadar düşmüştür. C. noacki'nin 50 bireye kadar konukçusunu çok rahat parazitleyebildiği, ancak bu yoğunluktan sonra parazitleme oranında düşme meydana geldiği tespit edilmiştir (Tablo. 3). Bu, denemeye alınan parazitoit dişilerinin performansının düşüklügüne ya da birey sayısının artmasıyla artan balımsı madde nedeniyle parazitoitin konukçusuna rahatça yaklaşarak onu parazitleyememesine bağlanabilir.

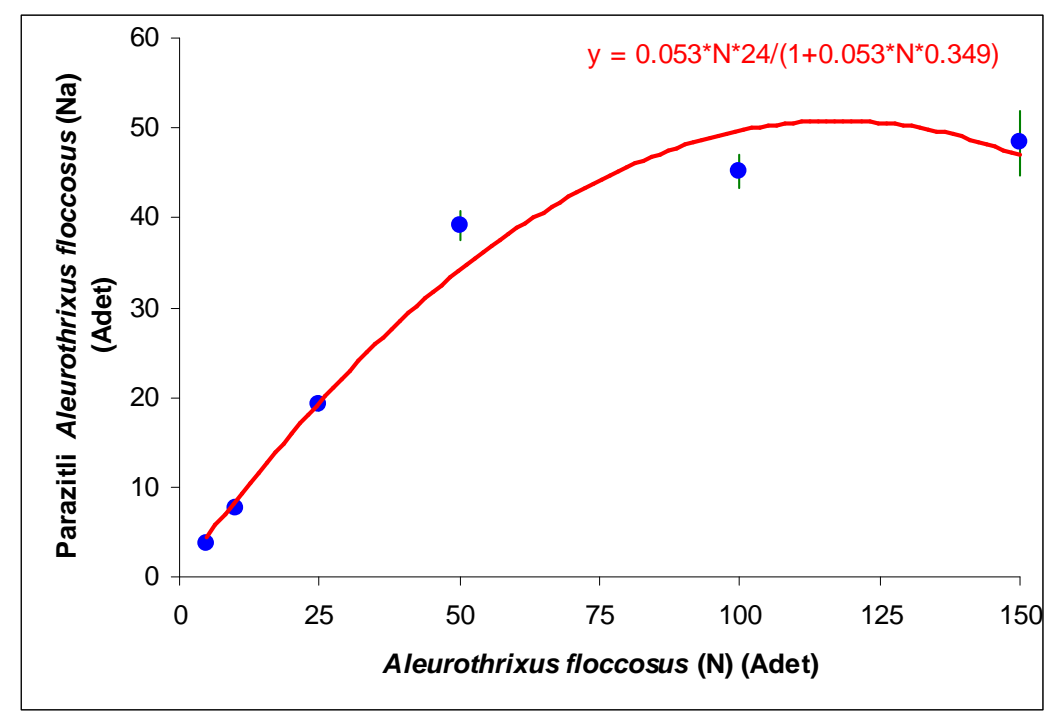

Şekil 2. Aleurothrixus floccosus'un farklı larva yoğunluklarında, Cales noacki'nin işlevsel tepkisi. 
C. noacki'nin A. floccosus üzerindeki işlevsel tepkisi, doğrusal olmayan regresyon eğrisi çizilerek hesaplanmıştır (Şekil. 2). Şekil. 2'deki regresyon eğrisinden de görülebileceği gibi parazitlenme 5 ile 50 larva seviyesine kadar hızlı bir şekilde artmış, ancak 50 larva seviyesinden sonra bu artış oldukça yavaşlayarak, eğim düz bir platoya dönüşme eğilimine girmiştir. C. noacki'nin doğada bulunan birçok parazitoit ve predatör ile benzer şekilde II. tipte işlevsel tepki eğrisi oluşturduğu [18], bu nedenle parazitoitin parazitleyebileceği maksimum birey sayısına ulaşıncaya kadar parazitleme oranının sürekli arttığı, maksimum parazitlediği birey sayısından sonra ise eğrinin sabitleştiği tespit edilmiştir. Bir başka beyazsinek parazitoiti olan Eretmocerus debachi Rose and Rosen (Hymenoptera: Aphelinidae)'nin II. tip işlevsel tepki eğrisini gösterdiği ve parazitoite Parabemisia myricae (Kuwana) (Homoptera: Aleyrodidae)'nin farkl1 yoğunlukları verildiğinde, en fazla parazitlenen birey sayısının 150 adet $P$. myricae yoğunluğunda ortaya çıktığı belirtilmiştir [22]. Benzer şekilde Encarsia formosa Gahan, 1924 (Hymenoptera: Aphelinidae)'nın Bemisia tabaci (Gennadius, 1889) (Hemiptera: Aleyrodidae)'nin dördüncü larva dönemleri üzerinde [23] ve Trialeurodes vaporariorum (Westwood, 1856) (Hemiptera: Aleyrodidae)'un farklı larva dönemleri üzerinde beslendiğinde II. tip işlevsel tepki sergilediği bildirilmiştir [24].

Holling' in disk eşitliğinden hesaplanan parametreler [ $a=$ parazitoitin konukçusunu anlık arama hızı, $T_{h}=$ parazitoitin konukçusunu arama ve beslenmesi için geçen süre, $1 / T_{h}=$ Parazitleme hızı (deneme süresince parazitlenebilecek larva sayısı) ve $R^{2}$ ] [18] Tablo 4.'de verilmiştir. C. noacki dişilerine A. floccosus'un farklı yoğunlukları verildiğinde, bir konukçu larvasını arama bulma hızının (a) $0.053 \pm 0.012$, konukçuyu başarılı bir şekilde parazitleyebilmesi $\left(T_{h}\right)$ için ise $0.349 \pm 0.049$ saate ihtiyaç duyduğu belirlenmiştir. Ayrıca, parazitoitin tüm yaşamı boyunca maksimum 68.77 adet $A$. floccosus ikinci dönem larvasını parazitleyebildiği ve $R^{2}$ değerinin (0.967) ise oldukça yüksek olduğu bulunmuştur (Tablo. 4). Bir başka beyazsinek parazitoiti olan $E$. formosa'nın, $T$. vaporariorum'u parazitleyebilmek için 0.041 saate (2.5 dakika) [25], $B$. tabaci'yi parazitleyebilmek için ise 0.066 saate (4 dakika) [26] ihtiyaç duyduğu bildirilmiştir. Benzer bir çalışmada ise yaprak başına beş adet $T$. vaporariorum verildiğinde, E. formosa'nın, bir tek bireyi parazitleyebilmek için 2.21 saate (132.6 dakika) gereksinim duyduğu belirtilmiştir [27]. E. formosa, yapılan ilk çalışmada $T$. vaporariorum'u ikinci yapılan çalışmadakinden çok daha kısa sürede parazitlemiştir. Bunun nedeni olarak araştırıcıların çalışma koşullarının ve konukçunun farklılığından kaynaklandığını belirtmişlerdir. E. formosa için gerekli olan bu sürenin, C. noacki' nin konukçusunu parazitleyebilmesi için gerekli olan süreden daha kısa olduğu ve parazitoitin konukçusunu arayıp parazitleyebilmek için çok fazla enerji sarfetmesine gerek olmadığı anlaşılmaktadır.

Tablo 4. Cales noacki'nin işlevsel tepki parametreleri (Ort. \pm S.H.).

\begin{tabular}{cccc}
\hline \hline$a \pm$ A.S.H. & $T_{h} \pm$ A.S.H. (Saat) & $1 / T_{h}$ & $R^{2}$ \\
\hline $0.053 \pm 0.012$ & $0.349 \pm 0.049$ & 68.77 & 0.967 \\
\hline
\end{tabular}

[a= Anlık arama hızı; Th= Başarılı bir parazitleme için geçen süre (arama, bulma, yoklama, parazitleme, işaretleme, dinlenme dahil), 1/Th= Parazitleme hızı (deneme süresince (24 saat) parazitlenebilecek larva sayıs1, A.S.H= Asimptotik standart hata]

C. noacki' nin konukçusunu anlık arama ve bulma hızının $0.053 \pm 0.012$ olduğunu göz önüne alarak bu değeri turunç fidanlarının ortalama yaprak alanına oranladığımızda (25 
$\mathrm{cm}^{2}$ ), parazitoitin A. floccosus'u yaprak üzerinde parazitleme değerinin $1.33 \mathrm{~cm}^{2}$ alan/gün olduğu hesaplanmıştır.

Parazitleme hızı değeri $\left(1 / T_{h}\right)$, konukçuların yalnızca parazitlenmesi için geçen süre değildir. Bu süre ayrıca, parazitoitin konukçusunu arama ve parazitleme aktivitelerinin dışında kalan, beslenme, antenlerini temizleme, dinlenme vb. gibi faaliyetlerini de içermektedir [28]. Bunun yanı sıra karanlık ortamda parazitoitlerin aktif olmadıkları, hatta ovipozisyonun bu süre boyunca azaldığı ve bu durumun parazitoitin konukçusunu arayıp parazitleyebilmesi için geçen süreyi etkileyebildiği bilinmektedir [29]. $\mathrm{Bu}$ çalışmada tespit edilen $C$. noacki'nin beyazsineği bulup parazitleyebilmesi için gereken değer (0.349 saat) için de bu konuyu göz önünde bulundurmamız gerekmektedir. Yani bu çalışmada belirlenen parazitoitin konukçusunu parazitleyebilmek için geçen süre (0.349 \pm 0.049, yaklaşı 20.9 dakika) içerisinde parazitoit birçok faaliyetini gerçekleştirdiği gibi belki de karanlık ortamda konukçusunu arayıp parazitlemek yerine dinlenmeyi tercih ettiği göz önünde tutulmaktadır.

C. noacki'nin farklı A. floccosus yoğunluklarında Holling'in II. tip işlevsel tepki eğrisine çok iyi bir şekilde uyum gösterdiği tespit edilmiştir [18]. Ancak birçok araştırıcı, bir parazitoitin yalnızca II. tip işlevsel tepki sergilemesinin konukçusunun popülasyonunu düzenlemede yeterince başarılı olamayabileceğini bildirmişlerdir. Buna bağlı olarak da parazitoitlerin farklı konukçu, çevresel faktörler ve sicaklık değişimlerinde farklı tipte işlevsel tepkiler sergileyebildikleri belirtilmiştir [30, 31]. Holling'in II nolu denkliğini gösteren doğal düşmanların, konukçu popülasyonlarını doğal olarak baskı altına alamayabilecekleri ve bunların zararlıların biyolojik mücadelesinde kullanılabilmesinin ancak doğal düşmanların doğaya salımları veya popülasyonlarını arttırıcı desteklemelerle başarılı olabilecekleri ifade edilmiştir [28, 32, 33].

Yapılan denemeler, gözlemler ve daha önce yapılan çalışmalar 1şığında, C. noacki'nin A. floccosus'un mücadelesinde başarılı bir biyolojik mücadele etmeni olduğu, özellikle doğa koşullarında zararlıyı baskı altına almada etkili olabileceği, ancak parazitoitle ilgili, konukçu yoğunluklarının belirlenmesi ve farklı konukçu larva dönemleri üzerindeki işlevsel tepkisi gibi çalışmaların yürütülmesinin, C. noacki' nin tanınmasında önemli katkılar sağlayacağı kanısına varılmıştır. Nitekim Holling'in II. tip işlevsel tepkisini [18] gösteren E. debachi [22], Eretmocerus mundus Mercet, 1931 (Hymenoptera: Aphelinidae) [34], E. formosa [35] ve Anagyrus kamali Moursi, 1948 (Hymenoptera: Encyrtidae) [36] gibi birçok doğal düşman da C. noacki gibi, konukçularını doğa koşullarında rahatlıkla baskı altında tutmaktadırlar.

\section{Kaynaklar}

[1] Onnilon, J.C. ve Onnilon, J., Contribution à l'étude de la dynamique des populations d'Homoptères infeodes aux agrumes. III. Introduction dans les Alpes-Maritimes de Cales noacki How. (Hym. Aphelinidae) parasite d'Aleurothrixus floccosus Mask. (Hom.) (Aleyrodidae). Comptes Rendus Hebdomadaires Des Seances De l'Academie Des Sciences. 58, 365-703, (1972).

[2] Carrero, J.M., Primera contributional al estudio de la biologia de la "mosca blanca" de los agrios, Aleurothrixus floccosus Mask., en la region valenciana. 
IV. Parasitismo por Cales noacki How. Anales del INIA. Serie: Protección Vegetal (España) 9, 153-162, (1975).

[3] Onnilon, J.C., A propos de la présence en France d'une nouvelle espèce d'Aleurode nuisible aux citrus Aleurothrixus floccosus Mask. (Homopt., Aleurodidae). Comptes Rendus Hebdomadaires Des Seances De l'Academie Des Sciences, 55, 937-941, (1969).

[4] Ulusoy, M.R. ve Uygun, N., Doğu Akdeniz Bölgesi turunçgillerinde potansiyel iki yeni zararlı: Aleurothrixus floccosus (Maskell) ve Paraleyrodes minei Iaccarino (Homoptera, Aleyrodidae). Türkiye Entomoloji Dergisi, 20, 2, 113121, (1996).

[5] Anonymous, Biological Control of Woolly Whitefly. California Agriculture, 30, 5, 4-8 p., (1976).

[6] Chermiti, B. ve Onnilon, J.C., A. propos de la presence en Tunisie de deux nouvelles especes d'leurodes nuisibles aux agrumes, Aleurothrixus floccosus (Maskell) et Parabemisia myricae (Kuwana) (Homoptera: Aleyrodidae). Fruits, 47, 3, 405-411, (1992).

[7] Longo, S., Rapisarda, C. ve Russo, A., Results of the biological control of Aleurothrixus floccosus (Maskell) in citrus orchards of eastern Sicily. XIV Congresso Nazionale Italiano di Entomologia, 28 maggio-1 giugno, 841-848, (1985).

[8] Vivas, A.G., Present status of whitefly on citrus in Spain, and control guidelines. Seminaire de la commision de technique, le 2 et 3 Septembre, Antalya Turquie, 1-19, (1992).

[9] Barbagallo, S., Longo, S., Rapisarda, C. ve Siscaro, G., Status of the biological control against citrus whiteflies and scale insects in Italy. Proceedings of the International Society of Citriculture, 3, 1216-1220, (1993).

[10] Rose, M. ve Woolley, J.B., Previously imported parasite may control invading whitefly. California Agriculture, 38, 3, 24-25, (1984).

[11] Miklasiewicz, T.J. ve Walker, G.P., Population dynamics and biological control of the woolly whitefly (Homoptera: Aleyrodidae) on citrus. Environmental Entomology, 19, 5, 1485-1490, (1990).

[12] Del-Bene, G. ve Gargani, E., Osservazioni su Aleurothrixus floccosus (Mask.) (Hom.: Aleyrodidae) e sul suo antagonista Cales noacki How. (Hym. Aphelinidae) in Toscana. Redia, 74, 1, 111-126, (1991).

[13] Vivas, A.G., Present status of whitefly on citrus in Spain, and control guidelines. Seminaire de la commision de technique, le 2 et 3 Septembre, Antalya Turquie, 1-19, (1992).

[14] Katsoyannos, Ifantis, P., K. ve Kontodimas, D.C., Phenology, Population Trend and Natural Enemies of Aleurothrixus floccosus (Hom.: Aleyrodidae) at a Newly Invaded Area in Athens, Greece. Entomophaga, 42, 4, 619-628, (1997).

[15] Ulusoy, M.R., Vatansever, G., Erkılıç, L. ve Uygun, N., Studies on Aleurothrixus floccosus (Maskell) (Homoptera, Aleyrodidae) and its parasitoid, Cales noacki Howard (Hymenoptera, Aphelinidae) in the East Mediterranean Region of Turkey. Journal of Pest Science, 76, 6, 163-169, (2003).

[16] Steel, R.G.D. ve Torrie, J.H., Principles ve Procedures of Statistics. Mc GraçHill Book Co., NEW YORK, p: 481, (1960).

[17] Karman, M., Bitki Koruma Araştırmalarında Genel Bilgiler. Denemelerin Kuruluşu ve Değerlendirme Esasları. T.C. Tar. Bak. Zir. Gn. Md. Yayınları Böl. Zir. Müc. Araştır. Enst., Bornova, İZMİR, 279 s., (1971). 
[18] Holling, C.S., Some characteristics of simple types of predation and parasitism. Canadian Entomolologist, 91, 385-398, (1959).

[19] Lo Pinto, M., "Ultreriori Notizie Bioetologiche su Cales noacki How. (Hym. Aphelinidae)". Estratto da Phytophaga, 4, 93-111, (1993)

[20] Onnilon, J.C. ve Onnilon, J.C., Contribution à l'étude de la dynamique des populations d'Homoptères inféodés aux agrumes. III. 2-Modalités de la dispersion de Cales noacki How. (Hymenoptera, Aphelinidae), parasite d'Aleurothrixus floccosus Mask. (Homoptera, Aleyrodidae). Bulletin SROP, 3, 55-66, (1974).

[21] Abbasi, M., Recherches sur deux homoptères fixés des citrus Aonidiella aurantii Mask. (Hom. Diaspididae) et Aleurothrixus floccosus Mask. (Hom. Aleyrodidae). Centre de Recherches Agronomiques de Rabat (1980).

[22] Şengonca, Ç., Uygun, N., Ulusoy, M.R. ve Kersting, U., Laboratory studies on biology and ecology of Eretmocerus debachi Rose and Rosen (Hymenoptera: Aphelinidae) the parasitoid of Parabemisia myricae (Kuwana) (Homoptera: Aleyrodidae). Journal of Applied Entomology, 118, 407-412, (1994).

[23] Enkegaard, A., Temperature dependent functional response of Encarsia formosa parasitizing the Poinsettia-strain of the cotton whitefly, Bemisia tabaci, on Poinsettia. Entomologia Experimentalis et Applicata 73, 19-29, (1994).

[24] Fransen, J.J. ve Monfort, M.A.J. van, Functional response and host preference of Encarsia formosa Gahan (Hymenoptera: Aphelinidae), a parasitoid of the greenhouse whitefly, Trialeurodes vaporariorum (Westwood) (Homoptera: Aleyrodidae). Journal of Applied Entomology, 103, 55-69, (1987).

[25] Lenteren, J.C. van ve Schaal, A.W.J. van der, Temperature thresholds for oviposition of Encarsia formosa, E. tricolor and E. pergandiella in larvae of Trialeurodes vaporariorum. Mededelingen van de Faculteit Landbouwwettenschappen Rijksuniversiteit (Gent), 46, 2, 457-464, (1981).

[26] Enkegaard, A., Encarsia formosa parasitizing the Poinsettia strain of the cotton whitefly, Bemisia tabaci, on Poinsettia: bionomics in relation to temperature. Entomologia Experimentalis et Applicata, 69, 251-261, (1993).

[27] Yano, E., Population responses of Encarsia formosa to the greenhouse whitefly and their role in population dynamics of whitefly- $E$. formosa system. Bulletin O.I.L.B/W.P.R.S, 10, 2, 193-197, (1987).

[28] Hassell, M.P., The dynamics of arthropod predator-prey systems. Monographs in Population Biology, 12, Princeton University Press, Princeton, N. J., (1978).

[29] Coker, R.A., The bionomics of Geocoris pallens Stal and Geocoris punctipes (Say) in cotton-alfaalfa agroecosystems with special reference to the biology of Telenomus reynoldsi, sp.n., a primary parasite of Geocoris eggs. - $\mathrm{PhD}$ dissertation, University of California, Riverside, (1973).

[30] Wang, B. ve Ferro, D.N., Functional responses of Trichogramma ostriniae (Hymenoptera: Trichogrammatidae) to Ostrinia nubilalis (Lepidoptera: Pyralidae) under laboratory and field conditions. Environmental Entomology, 27, 3, 752-758, (1998).

[31] Enkegaard, A., Brodsgaard, H.F., ve Hansen, D.L., Macrolophus caliginosus: Functional response to whiteflies and preference and switching capacity between whiteflies and spider mites. Entomologia Experimentalis et Applicata, 101, 81-88, (2001).

[32] Hassell, M.P. ve May, R.M., Stability in insect host - parasite models. Journal of Animal Ecology, 46, 249-262, (1973). 
[33] Murdoch, W.W. ve Oaten, A., Predation and population stability. Advances in Ecological Research, 9, 2-131, (1975).

[34] Jones, W.A., Greenberg, S.M. ve Legaspi, B. Jr., The effect of varying Bemisia argentifolii and Eretmocerus mundus ratios on parasitism. Biocontrol 44, 13-28, (1999).

[35] Roermund, H.J.W., Lenteren, J.C. van, ve Rabbinge, R., Analyses of Foraging Behavior of the Whitefly Parasitoid Encarsia formosa on a Leaf: A Simulation Study. Biological Control, 8, 22-36, (1997).

[36] Sagarra, L.A., Vincent, C., Peters, N.F. ve Stewart, R.K., Effect of host density, temperature and photoperiod on the fitness of Anagyrus kamali, a parasitoid of the hibiscus mealybug Maconellicoccus hirsutus. Entomologia experimentalis et Applicata, 96, 141-147, (2000). 